\title{
CONDICIONAMENTO OSMÓTICO DE SEMENTES DE Sesbania virgata (CAV.) PERS (FABACEAE)
}

\author{
Tathiana Elisa Masetto ${ }^{1 *}$, José Márcio Rocha Faria², Ana Carla Resende Fraiz ${ }^{3}$, Rodrigo Kelson Silva Rezende
}

*Autora para correspondência: tmasetto@gmail.com

\begin{abstract}
RESUMO: Conduziu-se este trabalho, com o objetivo de avaliar o efeito do condicionamento osmótico sobre a germinação e o vigor de sementes de Sesbania virgata. Foram utilizadas sementes escarificadas em ácido sulfúrico concentrado durante 40 minutos e, posteriormente, embebidas em soluções de PEG 8000 com os potenciais osmóticos de 0,$0 ;-0,2 ;-0,4 ;-0,6$ e - 0 ,8 MPa durante 12, 24 e 48 horas. Após o condicionamento, as sementes foram submetidas à secagem em sílica gel até que fosse atingido o grau de umidade inicial das sementes e, posteriormente, foram envelhecidas artificialmente $\left(40{ }^{\circ} \mathrm{C} / 48 \mathrm{~h} / 100 \% \mathrm{UR}\right)$. Os efeitos do condicionamento e do envelhecimento foram avaliados por meio do teste de germinação, primeira contagem e índice de velocidade de germinação. O osmocondicionamento das sementes beneficiou a germinação e o vigor das sementes de Sesbânia, submetidas ou não ao envelhecimento acelerado. O período de 24 horas de condicionamento favoreceu o desempenho das sementes osmocondicionadas.
\end{abstract}

Palavras-chave: Priming, envelhecimento acelerado, teor de água.

\section{OSMOPRIMING ON Sesbania virgata (CAV.) PERS (FABACEAE) SEEDS}

\begin{abstract}
This study evaluated the effect of the osmopriming on germination and vigour of Sesbania virgata seeds. Seeds were chemically scarified in concentrated sulphuric acid for 40 minutes and put to germinate either directly or after being submitted to osmopriming, drying and accelerated aging. Osmopriming was carried out with polyethylene glycol solutions (PEG 8000) at the following osmotic potentials-0.2; -0.4; -0.6 and -0.8 MPa for 12, 24 and 48 hours. After osmopriming, seeds were dried in silica gel until the initial moisture content was reached, and then submitted to the accelerated aging (48 h/100\% RH). The effects of osmopriming and accelerated aging were evaluated through germination test, first counting germination and germination speed index. The osmopriming, followed or not by accelerated aging, positively influenced germination and vigour of Sesbania virgata seeds.
\end{abstract}

Key words: Priming, accelerated aging, moisture content.

\section{INTRODUÇÃO}

Sesbânia (Sesbania virgata (CAV.) PERS) é um arbusto pertencente à família Fabaceae, (ARAÚJO et al., 2004). Ocorre em matas de galerias de regiões tropicais e está associada com os estágios iniciais da sucessão ecológica (POTOMATI; BUCKERIDGE, 2002). Apresenta potencial para revegetação de áreas degradadas sujeitas a inundações periódicas, em razão da tolerância a condições de baixa oxigenação e deficiências minerais do solo (KOLB et al., 2002). Forma simbiose radicular com rizóbio e, assim, sua capacidade de fixar nitrogênio no solo permite seu crescimento rápido em solos deficientes, favorecendo a sua utilização como adubo verde (RODRIGUES et al., 2003).

Sementes de alta qualidade e com germinação rápida e uniforme são essenciais no processo de produção de mudas e para o estabelecimento das plantas utilizadas como adubo verde, pois de acordo com Bevilacqua et al. (2008), as plantas recuperadoras de solo representam uma importante ferramenta para a melhoria e manutenção da qualidade química e física do solo, e ainda, observa-se que a produção de sementes dessas espécies pode representar ainda fonte de renda para a agricultura familiar, em razão do alto valor das sementes e à carência das mesmas no mercado. Até o momento, não há um sistema organizado de produção de sementes do gênero Sesbania, por isso, as sementes empregadas no cultivo são ainda de baixa qualidade. Em alguns genótipos, a baixa germinação e a emergência em campo reduzida são, também, decorrentes da alta porcentagem de sementes dormentes (VARI et al., 2004).

A técnica de condicionamento osmótico permite germinação rápida e formação de estande uniforme, prérequisitos fundamentais para o sucesso da produção de mudas. O osmocondicionamento consiste de hidratação controlada das sementes, suficiente para promover atividade pré-metabólica, sem permitir a protrusão da radícula. Nessa técnica, ocorre a embebição das sementes em soluções osmóticas, como, por exemplo, o polietileno glicol, por um período de tempo determinado e, em seguida, a secagem até que seja alcançado o teor de

\footnotetext{
${ }^{1}$ Universidade Tecnológica Federal do Paraná - Pato Branco, Paraná, Brasil

${ }^{2}$ Universidade Federal de Lavras - Lavras, Minas Gerais, Brasil

${ }^{3}$ Universidade Federal de Viçosa - Viçosa, Minas Gerais, Brasil

${ }^{4}$ Universidade Federal da Grande Dourados - Dourados, Mato Grosso do Sul, Brasil
}

Cerne, Lavras, v. 19, n. 4, p. 629-636, out./dez. 2013 
água original das sementes. No osmocondicionamento, a semente hidrata lentamente, o que permite um maior tempo para a reparação ou reorganização das membranas, possibilitando que os tecidos se desenvolvam de maneira mais ordenada e reduzindo os riscos da ocorrência de danos no eixo embrionário, causados pela rápida absorção de água (MENEZES et al., 2006). O condicionamento de sementes tem contribuído para melhorar o desempenho e resistência de plântulas aos estresses edafo-climáticos, comuns em áreas degradadas.

$\mathrm{O}$ osmocondicionamento foi testado para várias espécies florestais, evidenciando a eficiência do método no desempenho das sementes condicionadas, como foi observado por Silva et al. (2005), onde o condicionamento osmótico das sementes de faveleira (Cnidosculus juercifolius Pax \& K. Hoffam) em potencial de $-0,7$ $\mathrm{MPa}$, por $48 \mathrm{~h}$ foi benéfico para sementes com baixo vigor. Kissmann et al. (2010), observaram que o osmocondicionamento no potencial de $-1,0 \mathrm{MPa}$ não alterou significativamente o desempenho fisiológico das sementes de duas espécies de barbatimão ( $S$. obovatum e S. polyphyllum), mas foi prejudicial ao desenvolvimento de $S$. adstringens, entretanto, o condicionamento das sementes de $S$. adstringens e $S$. polyphyllum em potencial de $-0,5 \mathrm{MPa}$ promove maior porcentagem e velocidade de germinação. No entanto, de acordo com Santos et al. (2011), embora o condicionamento osmótico de sementes tenha sido largamente estudado nas últimas duas décadas, ainda existe a necessidade de expandir o conhecimento básico sobre diferentes aspectos relacionados com essa técnica, principalmente para espécies nativas e florestais. No que envolve a praticidade do tratamento, vários aspectos devem ser focalizados, como padronização e uso da metodologia para cada espécie; como a identificação da combinação mais eficiente entre o tempo de exposição das sementes e o potencial hídrico da solução osmótica (BARBEDO et al., 1997).

Contudo, não há relatos sobre os efeitos do condicionamento osmótico em sementes de Sesbania virgata. Considerando-se que o osmocondicionamento propicia a uniformidade da germinação, objetivou-se avaliar o efeito do condicionamento osmótico sobre a qualidade fisiológica das sementes de Sesbania virgata.

\section{MATERIAL E MÉTODOS}

Foram manualmente coletados frutos maduros de aproximadamente 40 matrizes na região de Ijaci $\left(21^{\circ}\right.$ $\left.10^{\prime} \mathrm{S}, 44^{\circ} 54^{\prime} \mathrm{W}\right)$, localizada ao sul de Minas Gerais, no mês de fevereiro de 2006. Após a coleta, os frutos foram levados ao Viveiro Florestal do Departamento de Ciências Florestais da Universidade Federal de Lavras (UFLA), Lavras, MG. O beneficiamento consistiu na quebra dos frutos no interior de saco de aniagem com martelo de borracha, de acordo com Davide et al. (1995).

Inicialmente, foi utilizado tratamento com ácido sulfúrico concentrado (densidade 1,84) durante 40 minutos para a superação da dormência tegumentar que as sementes de Sesbania virgata apresentam. Após o tratamento com ácido, as sementes foram lavadas em água corrente durante 10 minutos. Em seguida, foram desinfestadas em solução de hipoclorito de sódio a $2 \%$ durante 2 minutos e, então, submetidas ao teste de germinação sobre papel dentro de bandejas (controle). $\mathrm{O}$ experimento foi conduzido em B.O.D. à temperatura de $25^{\circ} \mathrm{C}$ e luz branca constante (quatro lâmpadas fluorescentes de $20 \mathrm{~W}$, proporcionando uma densidade de fluxo, aproximada de $0,012 \mathrm{w} \cdot \mathrm{m}^{-2} \cdot \mathrm{nm}^{-1}$ ).

Para o condicionamento osmótico das sementes de Sesbania virgata, após o tratamento com ácido, as sementes foram incubadas em placas de Petri, forradas com duas folhas de papel de filtro umedecidas com $20 \mathrm{~mL}$ de solução de PEG 8000 nos potenciais hídricos de -0,2; -0,4; $-0,6$ e -0,8 MPa por 12, 24 e 48 horas. As concentrações foram obtidas de acordo com Michel e Kaufmann (1973) sob temperatura de $25^{\circ} \mathrm{C}$. Paralelamente, foi determinado o teor de água das sementes após cada período na solução de PEG e as sementes foram retiradas, lavadas em água corrente para a remoção dos resíduos de PEG e secas sobre papel toalha durante 10 minutos, em condições de temperatura e umidade relativa do ambiente. Posteriormente, as sementes foram submetidas à secagem em sílica gel ativada ( $8 \%$ ) no interior de sala climatizada $\left(20^{\circ} \mathrm{C} / 60 \% \mathrm{UR}\right)$ até que fosse atingido o teor de água inicial aproximado, sendo em seguida submetidas ao envelhecimento acelerado $\left(40{ }^{\circ} \mathrm{C} / 48 \mathrm{~h} / 100 \%\right.$ UR) e ao teste de germinação da mesma forma citada anteriormente.

Para avaliar a eficiência do condicionamento osmótico sobre a germinação e o vigor das sementes, foram calculados a porcentagem de germinação, o índice de velocidade de germinação, obtido pela soma do número de sementes germinadas a cada dia, dividido pelo respectivo número de dias transcorridos a partir da semeadura, conforme Maguire (1962) e a primeira contagem do teste de germinação, sendo realizada aos cinco dias e a última contagem após sete dias da semeadura, conforme consta para as sementes de Sesbania exaltata nas Regras para Análise de Sementes (BRASIL, 1992).

Cerne, Lavras, v. 19, n. 4, p. 629-636, out./dez. 2013 
Para todos os testes descritos, foram utilizadas quatro repetições de 50 sementes. As observações foram realizadas diariamente, considerando germinadas as sementes que apresentavam raiz primária maior ou igual a $5 \mathrm{~mm}$. O teor de água das sementes foi determinado pelo método da estufa a $103{ }^{\circ} \mathrm{C} / 17 \mathrm{~h}$ (BRASIL, 1992), com quatro repetições de $1 \mathrm{~g}$ de sementes.

$\mathrm{O}$ delineamento experimental utilizado foi inteiramente casualizado, com quatro repetições, em esquema fatorial $4 \times 3 \times 2+1$, envolvendo quatro potenciais osmóticos de PEG 8000: -0,2; -0,4; -0,6 e -0,8 MPa, três períodos de condicionamento: 12, 24 e $48 \mathrm{~h}$, presença e ausência de envelhecimento acelerado e um tratamento adicional (controle). Os resultados obtidos foram submetidos à análise de variância e as médias comparadas entre si pelo teste t e Scott-Knott a 5\% de probabilidade.

\section{RESULTADOS E DISCUSSÃO}

Após o beneficiamento, as sementes apresentaram $7 \%$ de teor de água. O teor de água das sementes após os diferentes períodos de incubação nas soluções de PEG, secagem em sílica gel e envelhecimento acelerado encontram-se na Tabela 1. Embora não tenham sido analisados estatisticamente, os teores de água atingidos após a secagem e envelhecimento acelerado foram semelhantes para todos os grupos. As sementes incubadas no potencial hídrico mais negativo $(-0,8 \mathrm{MPa})$ alcançaram menores teores de água em relação às sementes condicionadas nos demais potenciais osmóticos, assim como para sementes de Esenbeckia leiocarpa (CÓRDOBA et al., 1995). Conforme o aumento do período de condicionamento de 24 para 48 horas, o teor de água das sementes praticamente não se alterou, independente do potencial osmótico utilizado, sugerindo que com 24 horas de embebição as sementes se encontravam em equilíbrio de absorção de água ou fase II da embebição (BEWLEY; BLACK, 1994).

Durante o processo de condicionamento osmótico, o maior tempo de permanência das sementes na fase II de embebição permite o início de eventos metabólicos prégerminativos, que favorecem, posteriormente, a germinação (BRAY, 1995). Esse autor sugere que para muitas das espécies estudadas, durante o condicionamento osmótico não se observa síntese de DNA. Entretanto, poucas horas após o início da germinação observa-se a retomada dos processos de duplicação do DNA e divisão celular.

Houve interação significativa entre o tempo de condicionamento e o envelhecimento acelerado. Pela Tabela 2, observa-se que as sementes que foram envelhecidas após 24 e 48 horas de embebição nas soluções
Tabela 1 - Teor de água das sementes de Sesbania virgata após 12, 24 e 48 horas de embebição em soluções de PEG 8000 com diferentes potenciais hídricos, submetidas à secagem em sílica gel e envelhecimento acelerado. Lavras, MG, 2009.

Table 1 - Water content of Sesbania virgata seeds after 12, 24 and 48 hours of soaking in PEG 8000 solutions with different water potentials, submitted at dehydration in silica gel and accelerated ageing.

\begin{tabular}{ccccc}
\hline $\begin{array}{c}\text { Tempo de } \\
\text { incubação }\end{array}$ & $\begin{array}{c}\text { Potencial } \\
\text { hídrico } \\
(\mathrm{MPa})\end{array}$ & $\begin{array}{c}\text { Teor de } \\
\text { água } \\
(\%)\end{array}$ & $\begin{array}{c}\text { Após } \\
\text { secagem em } \\
\text { sílica gel (\%) }\end{array}$ & $\begin{array}{c}\text { Após } \\
\text { envelhecimento } \\
\text { acelerado (\%) }\end{array}$ \\
\hline \multirow{4}{*}{ 12h } & $-0,2$ & 27,42 & 13,91 & 34,72 \\
& $-0,4$ & 29,53 & 13,21 & 44,49 \\
& $-0,6$ & 20,32 & 12,18 & 33,65 \\
& $-0,8$ & 17,25 & 13,16 & 28,88 \\
\hline \multirow{4}{*}{$24 \mathrm{~h}$} & $-0,2$ & 45,26 & 10,90 & 48,66 \\
& $-0,4$ & 43,86 & 11,90 & 38,11 \\
& $-0,6$ & 43,83 & 15,15 & 35,13 \\
& $-0,8$ & 30,90 & 12,12 & 35,45 \\
\hline \multirow{4}{*}{$48 \mathrm{~h}$} & $-0,2$ & 40,64 & 11,80 & 28,84 \\
& $-0,4$ & 44,08 & 15,90 & 34,33 \\
& $-0,6$ & 43,23 & 10,60 & 35,02 \\
& $-0,8$ & 33,94 & 14,83 & 30,57 \\
\hline
\end{tabular}

Tabela 2 - Germinação (\%) de sementes de Sesbania virgata de acordo com o tempo de osmocondicionamento (h), seguido ou não pelo envelhecimento. Lavras, MG, 2009.

Table 2-Germination (\%) of Sesbania virgata seeds according to the osmotic conditioning time (h), followed or not by aging.

\begin{tabular}{cccc}
\hline \multirow{2}{*}{ Envelhecimento } & \multicolumn{4}{c}{ Tempo de osmocondicionamento (h) } \\
\cline { 2 - 4 } & 12 & 24 & 48 \\
\hline Sim & $72 \mathrm{bB}$ & $96 \mathrm{aA}$ & $92 \mathrm{aA}$ \\
Não & $94 \mathrm{bA}$ & $98 \mathrm{aA}$ & $64 \mathrm{cB}$ \\
\hline
\end{tabular}

Médias seguidas de mesma letra minúscula na linha pelo teste de Scott-Knott e maiúscula na coluna pelo teste $t$, não diferem entre si $(\mathrm{P}<0,05)$.

de PEG apresentaram maior porcentagem de germinação em relação às sementes que permaneceram embebidas durante 12 horas. Para sementes não envelhecidas, o período de 24 horas de condicionamento proporcionou porcentagem de germinação significativamente maior ao final e à primeira contagem do teste (Tabela 3 ). Perez e Negreiros (2001) também observaram incremento na porcentagem de germinação e nos índices de velocidade

Cerne, Lavras, v. 19, n. 4, p. 629-636, out./dez. 2013 
Tabela 3 - Primeira contagem de germinação (\%) de acordo com o envelhecimento e tempo de incubação (h) durante o condicionamento osmótico para o ensaio com sementes de Sesbania virgata. Lavras, MG, 2009.

Table 3 - Average first counting of germination (\%) according to age and incubation time (h) of osmotic conditioning to the test with Sesbania virgata seeds.

\begin{tabular}{cccc}
\hline \multirow{2}{*}{ Envelhecimento } & \multicolumn{3}{c}{ Tempo } \\
\cline { 2 - 4 } & 12 & 24 & 48 \\
\hline Sim & $34,00 \mathrm{bB}$ & $47,00 \mathrm{aA}$ & $46,00 \mathrm{aA}$ \\
Não & $45,00 \mathrm{bA}$ & $48,00 \mathrm{aA}$ & $31,00 \mathrm{cB}$ \\
\hline
\end{tabular}

Médias seguidas de mesma letra minúscula na linha pelo teste de Scott-Knott e maiúscula na coluna pelo teste $t$ não diferem entre si $(\mathrm{P}<0,05)$.

de germinação de sementes de canafístula (Peltophorum dubium) pré-condicionadas em água e submetidas ao estresse salino. Suñé et al. (2002) também relataram os efeitos positivos sobre o vigor de sementes de Adesmia latifolia osmocondicionadas em solução de PEG.

Vale ressaltar que durante o condicionamento são iniciados vários processos como mobilização de reservas, ativação e síntese de DNA, produção de ATP, reparo de danos nas membranas e no aparato respiratório (CLARKE; JAMES, 1991; SUNG; CHANG, 1993) e ainda o acúmulo de solutos no decorrer do processo de germinação, resultando em um maior potencial de turgor celular, durante a reidratação das sementes, o que resultaria na protrusão da radícula em menor tempo (BRADFORD, 1986).

Ficou evidente o efeito positivo do condicionamento osmótico das sementes pelo parâmetro de primeira contagem (Tabela 4) e foi observada interação significativa entre o tempo de condicionamento e envelhecimento acelerado para a primeira contagem, sendo que sementes osmocondicionadas durante $24 \mathrm{~h}$ e envelhecidas ou não, não diferiram significativamente entre si e foram superiores às sementes osmocondicionadas durante $12 \mathrm{~h}$. Verificou-se que as sementes pré-condicionadas durante $48 \mathrm{~h}$ apresentaram resultado superior de primeira contagem em relação às sementes que não receberam o tratamento com PEG (Tabela 3), indicando os efeitos positivos do condicionamento osmótico. Houve interação significativa entre os potenciais osmóticos e envelhecimento acelerado das sementes (Tabela 5), sendo observado que sementes embebidas na solução osmótica de -0,2 MPa e, posteriormente envelhecidas, apresentaram maior porcentagem de germinação à primeira contagem em relação às não envelhecidas. Não foram verificados
Tabela 4 - Primeira contagem de germinação (\%) de sementes de Sesbania virgata para o tratamento adicional e para o fatorial. Lavras, MG, 2009.

Table 4 - First count germination (\%) of Sesbania virgata seeds for additional and for the factorial treatments.

\begin{tabular}{cc}
\hline Comparação & Médias \\
\hline Adicional & $82 \mathrm{~B}$ \\
Fatorial & $84 \mathrm{~A}$ \\
\hline
\end{tabular}

Médias seguidas de mesma letra maiúscula na coluna, não diferem entre si pelo teste $\mathrm{t}(\mathrm{P}<0,05)$.

Tabela 5 - Primeira contagem de germinação (\%) de acordo com as concentrações de PEG utilizadas no osmocondicionamento e envelhecimento para o ensaio com sementes de Sesbania virgata. Lavras, MG, 2009.

Table 5 - First count germination (\%) according to the concentrations of PEG used on osmoconditioning and aging for the test with Sesbania virgata seeds.

\begin{tabular}{ccc}
\hline \multirow{2}{*}{ Concentrações } & \multicolumn{2}{c}{ Envelhecimento } \\
& Sim & Não \\
\hline$-0,2$ & $44,00 \mathrm{aA}$ & $40,00 \mathrm{bA}$ \\
$-0,4$ & $42,00 \mathrm{aA}$ & $42,00 \mathrm{aA}$ \\
$-0,6$ & $41,00 \mathrm{aA}$ & $42,00 \mathrm{aA}$ \\
$-0,8$ & $42,00 \mathrm{aA}$ & $42,00 \mathrm{aA}$ \\
\hline
\end{tabular}

Médias seguidas de mesma letra minúscula na linha pelo teste F e maiúscula na coluna pelo teste de Scott-Knott não diferem entre si $(\mathrm{P}<0,05)$.

comportamentos diferenciados para essa característica no ensaio com sementes submetidas aos demais níveis de potenciais osmóticos $(-0,4 ;-0,6$ e - $0,8 \mathrm{MPa})$ e envelhecidas artificialmente ou não.

O índice de velocidade de germinação (IVG) mostrou-se sensível na avaliação do efeito do condicionamento osmótico (Tabela 6). Houve interação tripla significativa entre tempo de condicionamento, concentrações de soluções e envelhecimento acelerado, sendo observado IVGs estatisticamente superiores em sementes osmocondicionadas (Tabela 6). Para sementes não envelhecidas, as concentrações de $-0,2$ e $-0,4 \mathrm{MPa}$ combinadas com o período de 24 horas de condicionamento proporcionaram os maiores IVGs, sendo que para o potencial de $-0,6 \mathrm{MPa}$ os maiores resultados foram verificados com 12 e $48 \mathrm{~h}$ de incubação e não foram observadas diferenças significativas em relação aos períodos de condicionamento no potencial de $-0,8 \mathrm{MPa}$. Para as sementes envelhecidas

Cerne, Lavras, v. 19, n. 4, p. 629-636, out./dez. 2013 
Tabela 6 - Resultados médios do índice de velocidade de germinação (IVG) para o tratamento adicional e para o fatorial em ensaio com sementes de Sesbania virgata. Lavras, MG, 2009.

Table 6-Averages results for the germination speed index (IVG) and further treatment in the factorial experiment with seeds of Sesbania virgata.

\begin{tabular}{cc}
\hline Comparação & Médias \\
\hline Adicional & $17,19 \mathrm{~B}$ \\
Fatorial & $23,13 \mathrm{~A}$ \\
\hline
\end{tabular}

Médias seguidas de mesma letra maiúscula na coluna, não diferem entre si pelo teste $\mathrm{t}(\mathrm{P}<0,05)$.

não houve diferenças significativas entre os tratamentos de condicionamento osmótico (Tabela 7). Esses resultados permitem inferir que o condicionamento osmótico proporcionou efeitos positivos no potencial fisiológico das sementes de $S$. virgata, evidenciado pelos incrementos na velocidade de germinação das sementes.

Tabela 7 - Resultados médios do índice de velocidade de germinação (IVG) de acordo com as concentrações de PEG e tempo (h) usados no osmocondicionamento e para cada categoria de envelhecimento em ensaio com sementes de Sesbania virgata. Lavras, MG, 2009.

Table 7 -Averages results of the germination speed index (IVG) in accordance with the concentrations and time (h) used on the osmoconditioning for each category of aging test seeds of Sesbania virgata. Lavras, MG, 2009.

\begin{tabular}{ccccc}
\hline \multirow{2}{*}{ Envelhecimento } & Conc. & \multicolumn{4}{c}{ Tempo } \\
\cline { 2 - 5 } & & 12 & 24 & 48 \\
\hline \multirow{3}{*}{ Sim } & $-0,2$ & $24,09 \mathrm{aA}$ & $18,29 \mathrm{aA}$ & $17,96 \mathrm{aA}$ \\
& $-0,4$ & $20,79 \mathrm{aA}$ & $22,71 \mathrm{aA}$ & $17,41 \mathrm{aA}$ \\
& $-0,6$ & $23,16 \mathrm{aA}$ & $20,85 \mathrm{aA}$ & $19,23 \mathrm{aA}$ \\
& $-0,8$ & $21,19 \mathrm{aA}$ & $21,28 \mathrm{aA}$ & $17,12 \mathrm{aA}$ \\
\hline \multirow{3}{*}{ Não } & $-0,2$ & $15,99 \mathrm{cB}$ & $34,36 \mathrm{aA}$ & $26,43 \mathrm{bB}$ \\
& $-0,4$ & $12,92 \mathrm{bB}$ & $31,41 \mathrm{aA}$ & $16,34 \mathrm{bC}$ \\
& $-0,6$ & $32,11 \mathrm{aA}$ & $22,00 \mathrm{bB}$ & $33,16 \mathrm{aA}$ \\
& $-0,8$ & $30,97 \mathrm{aA}$ & $30,09 \mathrm{aA}$ & $25,10 \mathrm{aB}$ \\
\hline
\end{tabular}

Médias seguidas de mesma letra minúscula na linha e maiúscula na coluna (de acordo com a categoria de envelhecimento), não diferem entre si pelo teste de Scott-Knott $(\mathrm{P}<0,05)$.

Esses resultados são semelhantes aos encontrados sobre os efeitos benéficos no desempenho de sementes de outras espécies arbóreas tropicais. Em sementes de palmeira real (Archontophoenix alexandrae), verificouse que o condicionamento em água pelo período de 20 dias proporcionou maior índice de velocidade de germinação quando comparado com sementes que não foram condicionadas (TEIXEIRA et al., 2007); o hidrocondicionamento de $4 \mathrm{~h}$ a $15{ }^{\circ} \mathrm{C}$ mostrou ser uma opção econômica e de fácil aplicação em sementes de visgueiro (Parkia pendula), pois aumentou a velocidade do desenvolvimento das plântulas, a porcentagem de germinação das sementes não armazenadas em níveis similares aos das armazenadas e a sincronização da germinação em sementes armazenadas (PINEDO; FERRAZ, 2008); em sementes de jenipapo (Genipa americana) osmocondicionadas com PEG observouse aumento da porcentagem, índice de velocidade e velocidade de germinação nos tratamentos de 0,0 e $-0,3$ MPa (SANTOS et al., 2011).

As sementes condicionadas por 12 horas em soluções a -0,2 e -0,4 MPa e envelhecidas artificialmente apresentaram maiores IVGs quando comparadas às não envelhecidas, enquanto as sementes que permaneceram embebidas nas soluções de -0,6 e -0,8 MPa, independente do período, apresentaram maior IVG quando não foram submetidas ao envelhecimento acelerado (Tabela 8), sugerindo que sob potenciais osmóticos elevados o condicionamento osmótico não proporcionou benefícios ao índice de velocidade de germinação das sementes.

Para o período de 24 horas de condicionamento, em todas as concentrações estudadas, o IVG foi maior em sementes não envelhecidas artificialmente, sendo esse efeito também observado para o período de 48 horas de incubação nas soluções osmóticas, com exceção do potencial de $-0,4 \mathrm{MPa}$, que não proporcionou diferenças significativas do IVG entre as sementes envelhecidas ou não. $\mathrm{O}$ condicionamento osmótico de sementes, além de reduzir o tempo entre a semeadura e a emergência de plântulas, aumenta a tolerância das sementes às condições adversas de ambiente, ao permitir que ocorram as etapas iniciais do processo de germinação, sem, contudo, permitir a protrusão da radícula (BALBINOT; LOPES, 2006).

Os dados obtidos no presente trabalho referentes à porcentagem de germinação, primeira contagem e índice de velocidade de germinação para sementes osmocondicionadas não foram uniformes quanto aos efeitos deletérios do envelhecimento acelerado aplicado às sementes de $S$. virgata. Provavelmente, tal fato ocorreu em razão do lote utilizado ser constituído por sementes de alta qualidade, embora tenha sido observado que

Cerne, Lavras, v. 19, n. 4, p. 629-636, out./dez. 2013 
Tabela 8 - Resultados médios do índice de velocidade de germinação (IVG) de acordo com o envelhecimento para as categorias do tempo (h) e concentrações de condicionamento em ensaio com sementes de Sesbania virgata. Lavras, MG, 2009.

Table $\boldsymbol{8}$ - Averages results of the germination speed index (IVG) in accordance with age for the categories of time ( $h$ ) and concentrations in the conditioning test with seeds of Sesbania virgata.

\begin{tabular}{cccc}
\hline \multirow{2}{*}{ Tempo } & Conc. & \multicolumn{2}{c}{ Envelhecimento } \\
\cline { 2 - 4 } & & Sim & Não \\
\hline \multirow{3}{*}{12} & $-0,2$ & $24,09 \mathrm{a}$ & $15,99 \mathrm{~b}$ \\
& $-0,4$ & $20,79 \mathrm{a}$ & $12,92 \mathrm{~b}$ \\
& $-0,6$ & $23,16 \mathrm{~b}$ & $31,10 \mathrm{a}$ \\
& $-0,8$ & $21,19 \mathrm{~b}$ & $30,97 \mathrm{a}$ \\
\hline \multirow{3}{*}{24} & $-0,2$ & $18,29 \mathrm{~b}$ & $34,36 \mathrm{a}$ \\
& $-0,4$ & $22,71 \mathrm{~b}$ & $31,41 \mathrm{a}$ \\
& $-0,6$ & $19,24 \mathrm{~b}$ & $22,00 \mathrm{a}$ \\
& $-0,8$ & $21,29 \mathrm{~b}$ & $30,09 \mathrm{a}$ \\
\hline \multirow{2}{*}{48} & $-0,2$ & $17,96 \mathrm{~b}$ & $26,43 \mathrm{a}$ \\
& $-0,4$ & $17,41 \mathrm{a}$ & $16,36 \mathrm{a}$ \\
& $-0,6$ & $20,85 \mathrm{~b}$ & $33,16 \mathrm{a}$ \\
\hline
\end{tabular}

Médias seguidas de mesma letra minúscula na linha não diferem entre si pelo teste $\mathrm{F}(\mathrm{P}<0,05)$.

sementes incubadas em PEG apresentaram potencial fisiológico superior em relação às sementes que não foram submetidas aos tratamentos com PEG. No entanto, as informações sobre os efeitos do condicionamento osmótico em sementes de espécies florestais ainda são discrepantes na literatura, sendo verificado que sementes osmocondicionadas de Cedrela fissilis Vell. apresentaram redução no percentual de germinação quando submetidas ao envelhecimento acelerado (BARBEDO et al., 1997) e o condicionamento osmótico tornou as sementes de Chorisia speciosa mais sensíveis às condições impostas pelo teste de envelhecimento precoce, com redução acentuada de seu vigor (FANTI; PEREZ, 2003).

De maneira geral, os efeitos do condicionamento osmótico com soluções de PEG foram positivos para o desempenho de sementes de S. virgata em relação à germinação e ao vigor. Esses resultados são importantes pela eficiência da técnica na propagação e uniformidade de germinação, principalmente em razão das recomendação da espécie na prática de recuperação de áreas degradadas que exige a semeadura direta.

Cerne, Lavras, v. 19, n. 4, p. 629-636, out./dez. 2013

\section{CONCLUSÕES}

O condicionamento osmótico proporciona benefícios ao desempenho das sementes de $S$. virgata em relação à germinação e ao índice de velocidade de germinação de sementes submetidas ou não ao envelhecimento acelerado. O período de 24 horas de condicionamento favorece o desempenho das sementes osmocondicionadas.

\section{AGRADECIMENTOS}

Os autores agradecem à Fundação de Amparo à Pesquisa do Estado de São Paulo (Fapesp), pelo financiamento parcial do presente trabalho, por meio do Projeto No. 2005/04139-7.

\section{REFERÊNCIAS}

ARAÚJO, E. C.; MENDONÇA, A. V.; BARROSO, D. G.; LAMÔNICA, K. R.; SILVA, R. F. Caracterização morfológica de frutos, sementes e plântulas de Sesbania virgata Pers.

Revista Brasileira de Sementes, Londrina, v. 26, n. 1, p. $105-$ $110,2004$.

BALBINOT, E.; LOPES, H. M. Efeitos do condicionamento fisiológico e da secagem na germinação e no vigor de sementes de cenoura. Revista Brasileira de Sementes, Londrina, v. 28, n. 1, p. 1-8, 2006.

BARBEDO, C. J.; MARCOS FILHO, J.; NOVEMBRE, A. D. L. C. Condicionamento osmótico e armazenamento de sementes de cedro-rosa (Cedrela fissilis Vell). Revista Brasileira de Sementes, Londrina, v. 19, n. 2, p. 354-360, 1997.

BEVILACQUA, G. A. P.; ANTUNES, I. F.; ZUCHI, J.; MARQUES, R. L. L. Indicações técnicas para produção de sementes de plantas recuperadoras do solo para a agricultura familiar. Pelotas: EMBRAPA Clima Temperado, 2008. 43 p. (Documentos, 227).

BEWLEY, J. D.; BLACK, M. Seeds: physiology of development and germination. $2^{\text {nd }}$ ed. New York: Plenum, 1994.

BRADFORD, K. J. Manipulation of seeds water relations via osmotic priming to improve germination under stress conditions. Hortscience, Alexandria, v. 21, n. 5, p. 1105-1112, 1986. 
BRASIL. Ministério da Agricultura e da Reforma Agrária. Regras para análise de sementes. Brasília: SNDA/DNDV/ CLAV, 1992. 365 p.

BRAY, C. M. Biochemical process during the osmopriming of seeds. In: KIEGEL, J.; GALILI, G. (Ed.). Seed development and germination. New York: M. Dekker, 1995. p. 767-789.

CLARKE, N. A.; JAMES, P. A. The effects of priming and accelerated ageing upon the nucleic acid content of leek seeds and their embryos. Journal of Experimental Botany, Oxford, v. 42, n. 2, p. 261-268, 1991.

CÓRDOBA, G. A. T.; LIMA, B. E. E.; BORGES, R. C. G.; NEVES, J. C. L. Osmocondicionamento em sementes de Esenbeckia leiocarpa ENGL (guarantã). Revista Brasileira de Sementes, Londrina, v. 17, n. 2, p. 220-226, 1995.

DAVIDE, A. C.; FARIA, J. M. R.; BOTELHO, S. A. Propagação de espécies florestais. Belo Horizonte: CEMIG/ UFLA/FAEPE; Lavras: UFLA, 1995. 41 p.

FANTI, S. C.; PEREZ, S. C. J. G. A. Efeito do estresse hídrico e envelhecimento precoce na viabilidade de sementes osmocondicionadas de Chorisia speciosa. Pesquisa

Agropecuária Brasileira, Brasília, v. 38, n. 4, p. 537-543, abr. 2003.

KISSMANN, C.; SCALON, S. P. Q.; MOTA, L. H. S.; VIEIRA, M. C. Germinação de sementes de Stryphnodendron Mart. osmocondicionadas. Revista Brasileira de Sementes, Londrina, v. 32, n. 2, p. 26-35, 2010 .

KOLB, R. M.; RAWYLER, A.; BRAENDLE, R. Parameters affecting the early seedling development of four neotropical trees under oxygen deprivation stress. Annals of Botany, Oxford, v. 81, p. 551-558, 2002.

MAGUIRE, J. D. Speed of germination aid in selection and evaluation for seedling and vigour. Crop Science, Madison, v. 2, n. 2, p. 176-177, 1962.

MENEZES, N. L.; ESPÍNDOLA, M. C. G.; PASQUALLI, L. L.; SANTOS, C. M. R.; FRAZIN, S. M. Associação de tratamentos pré-germinativos em sementes de alface. Revista Faculdade Zootecnia Veterinária Agronomia, Uruguaiana, v. 13, n. 1, p. 85-96, 2006.
MICHEL, B. E.; KAUFMANN, M. R. The osmotic potential of poliethylene glycol 6000. Plant Physiology, Bethesda, v. 51, p. 914-916, 1973.

PEREZ, S. C. J.; NEGREIROS, G. F. Efeitos do précondicionamento na viabilidade e no vigor de sementes de canafístula (Peltophorum dubium (Spreng.) Taub.) em condições de estresse. Revista Brasileira de Sementes, Londrina, v. 23, n. 1, p. 175-183, 2001.

PINEDO, G. J. V.; FERRAZ, I. D. K. Hidrocondicionamento de Parkia pendula [BENTH ex WALP]: sementes com dormência física de árvore da Amazônia. Revista Árvore, Viçosa, v. 32, n. 1, p. 39-49, jan./fev. 2008.

POTOMATI, A.; BUCKERIDGE, M. S. Effect of abscisic acid on the mobilisation of galactomannan and embryo development of Sesbania virgata (Cav.) Pers. (Leguminosae Faboideae). Revista Brasileira de Botânica, São Paulo, v. 25, n. 3, p. 303-310, set. 2002.

RODRIGUES, L. A.; MARTINS, M. A.; SALOMÃO, M. S. M. B. Usos de micorrizas e rizóbio em cultivo consorciado de eucalipto e sesbânia. Revista Brasileira de Ciência do Solo, Viçosa, v. 27, p. 583-591, 2003.

SANTOS, A. R. F.; SILVA-MANN, R.; FERREIRA, R. A. Restrição hídrica em sementes de jenipapo (Genipa americana L.). Revista Árvore, Viçosa, v. 35, n. 2, p. 213220, fev. 2011.

SILVA, L. M. M.; AGUIAR, I. B.; MORAIS, D. L.; VIEGAS, R. A. Estresse hídrico e condicionamento osmótico na qualidade fisiológica de sementes de faveleira Cnidoscolus juercifolius. Revista Brasileira de Engenharia Agrícola e Ambiental, Campina Grande, v. 9, n. 1, p. 66-72, 2005.

SUÑÉ, A. D.; FRANKE, L. B.; SAMPAIO, T. G. Efeitos do condicionamento osmótico na qualidade fisiológica de sementes de Adesmia latifolia (Spreng.) Vog. Revista Brasileira de Sementes, Londrina, v. 24, n. 1, p. 18-23, 2002.

SUNG, F. J. M.; CHANG, Y. H. Biochemical activities associated with priming of sweet corn seeds to improve vigor. Seed Science and Technology, Zürich, v. 21, n. 1, p. 97-105, 1993.

Cerne, Lavras, v. 19, n. 4, p. 629-636, out./dez. 2013 
TEIXEIRA, M. T.; VIEIRA, H. D.; TEIXEIRA, S. L.; SILVA, R. F. Influence of disinfestation and osmotic conditioning on the germinating behavior of australian royal palm (Archontophoenix alexandrae) seeds. Revista Brasileira de Sementes, Londrina, v. 29, n. 1, p. 155-159, 2007.
VARI, A. K.; SHARMA, S. P.; JETHANI, I.; BARANWAL, S.; KHANNA, M. Seed testing procedures and seed standards of Sesbania (Dhaincha) and Crotalaria. New Delhi: Indian Agricultural Research Institute, 2004. Publication TB-ICN 28/2004.

Recebido: 6 de julho de 2011; aceito: 24 de maio de 2013.

Cerne, Lavras, v. 19, n. 4, p. 629-636, out./dez. 2013 